\title{
Distribution of $\alpha$-actinin-3 rs1815739 and angiotensin-1 converting enzyme InDel polymorphisms in Turkish bodybuilders
}

\author{
TOLGA POLAT $^{1}$, CANAN SERCAN DOGAN $^{1}$, MURAT DOGAN ${ }^{2}$, TEOMAN AKÇAY $^{3}$ and KORKUT ULUCAN ${ }^{1,4}$ \\ ${ }^{1}$ Laboratory of Medical Genetics and Molecular Diagnostics, Üsküdar University, Üsküdar, İstanbul 34662; \\ ${ }^{2}$ Department of Child Development, Nisantasi University, Vocational School, Istanbul 34481; \\ ${ }^{3}$ Department of Pediatric Endocrinology, İstinye University, Gaziosmanpaşa Medical Park Hospital, Istanbul 34250; \\ ${ }^{4}$ Department of Medical Biology and Genetics, Faculty of Dentistry, Marmara University, Istanbul 34854, Turkey
}

Received April 19, 2020; Accepted September 14, 2020

DOI: $10.3892 /$ br.2020.1374

\begin{abstract}
The determination of the genetic profiles of successful athletes and the effects of these genetic parameters on athletic performance is gaining increasing interest. The majority of studies assessing the genetics of athletes usually analyse the most well-known genetic variations in athletes associated with the different specialties. The aim of the present study was to analyse the ACE InDel and ACTN3 rs1815739 polymorphisms in Turkish bodybuilders. A total of 11 male bodybuilders were recruited and genotyped for these polymorphisms. The respective percentage of the ACE II, ID and DD genotypes were 18, 73 and 9. For the ACTN3 genotype, the respective frequencies were 55 and 45 for the RX and RR genotypes. No XX genotype was detected. The allelic counts were $12(55 \%)$ for I and $10(45 \%)$ for the D alleles of $A C E$; and $12(55 \%)$ and 10 (45\%) for R and $\mathrm{X}$ alleles, respectively, for the ACTN3 genotype. Additionally, 5 athletes had ID + RX genotypes in terms of ACE InDel and ACTN3 rs1815739 polymorphisms, respectively. These results indicate the importance of endurance related alleles of $A C E$ and $A C T N 3$ in bodybuilders. The results of the present are in agreement with previous studies, highlighting a potential association between specific polymorphisms and the endurance-related nature of bodybuilders. Further studies with larger cohorts are required to understand the association between these polymorphisms and specific parameters performance in bodybuilders.
\end{abstract}

\section{Introduction}

Athletic performance is a combination of innate genetic factors as well as several environmental factors, including

Correspondence to: Dr Korkut Ulucan, Laboratory of Medical Genetics and Molecular Diagnostics, Üsküdar University, Haluk Turksoy Sok., 14 Altunizade, Üsküdar, Istanbul 34662, Turkey

E-mail: korkut.ulucan@marmara.edu.tr

Key words: genetics, polymorphisms, sports genetics, bodybuilder, single nucleotide polymorphism, fitness nutrition, psychological factors and extent of training (1). The current body of research on athletic performance places a heavy focuses on genetic variants that contribute notably to the improved performance of individuals, as well as means of increasing performance $(2,3)$. Sports genetics studies include the determination of genes/gene polymorphisms affecting athletic performance, the determination of the molecular mechanisms regulated by these genes, and the determination of predispositions to enhanced athletic performance. These studies serve an important, role not only in individual sports, but also in nutrition, and in the design of physiological and psychological training programs suitable for the specific genetic profile of an athlete $(4,5)$.

Bodybuilding is a process of developing muscle fibres by combining weightlifting, calorie intake and other athletic applications. Although the most important characteristic of muscle development is the growth of muscle mass, aesthetics is also an important psychological effect, and the genetic endowment of an individual is one of the most important factor in the formation of these features. Strength and endurance are considered to be of utmost importance for successful bodybuilding $(6,7)$.

The first major study related to athletic performance assessed the angiotensin converting enzyme (ACE) gene (8). $A C E$ is located at $17 \mathrm{q} 23$ and encodes an angiotensin-1 transducer enzyme that is part of the renin-angiotensin system, and responsible for controlling blood pressure by regulating body fluid levels (9). The expression of the enzyme varies amongst individuals due to a variation in the gene. The $A C E$ I allele contains a $287 \mathrm{bp}$ Alu family insert and is associated with reduced enzyme activity (9). Conversely, the D allele is associated with increased serum levels and tissue $A C E$ activity (10). The $A C E$ II genotype is predominantly associated with enhanced endurance and increased efficiency of exercise, whereas the DD genotype is associated with increased power and power performance, although the specific effects of these alleles is contested $(11,12)$.

One of the most important gene regions affecting athletic performance is the $\alpha$-actin-3 (ACTN3) gene. ACTN3 is located on the long arm of the 11th chromosome (11q13.1), and encodes the $\alpha$-actin- 3 protein, which is responsible for the formation of rapid and strong muscle contractions during training that requires explosive muscle strength, such as weightlifting (13). This protein is found in the $\mathrm{Z}$ lines of the sarcomeres in skeletal muscle, and is 
involved in the binding of actin fibrils during muscle contraction. Thus, it has a notable role in determining muscle strength (14). The functional R577X polymorphism (rs1815739) occurs as a result of a cytosine-thymine alteration in the 16th exon of the gene. This single base change, which results in the formation of a stop $(\mathrm{X})$ codon instead of the codon $(\mathrm{R})$ encoding the arginine, constitutes a structural difference in the $\alpha$-actin-3 protein (15). The ACTN3 XX genotype is associated with endurance and the RR genotype is associated with enhanced sprinting ability (16).

To the best of our knowledge, the present study is the first to analyse the genetic profiles of Turkish bodybuilders, including assessment of the genetic polymorphisms harboured by them. The aim of the present study was to determine the distribution of ACTN3 rs1815739 and ACE InDel polymorphisms in Turkish bodybuilders.

\section{Materials and methods}

Study subjects. In the present study, 11 male bodybuilders (aged 18-23; three 18 years old volunteers, two 19-year olds, one 20 year old, three 21 year olds, a 22 year old and one 23 year old) volunteered to take part in the present study which was performed January 2019 and April 2019. The inclusion criteria for the volunteers was that they had to have won at least one medal in any kind of international competition. Athletes who were banned for any kind of doping activity or did not have any success in a competition were excluded from the present study. The bodybuilders recruited had substantial national and international success within the last 4 years and were still training actively, with a mean of 6 training sessions per week. The average weight of the bodybuilders was $91 \pm 2 \mathrm{~kg}$. The study protocol was approved by the Üsküdar University Ethics Committee and was performed in accordance with the principles of the Declaration of Helsinki 7th revision (17). All the bodybuilders were informed of the experimental procedure and any potential ethical implications, and all the participants provided written informed consent. The athletes' age, weight, success (medal status), parental consanguinity, presence of any genetically transmitted diseases, doping bans and ancestry was obtained.

Genotyping. DNA isolation from buccal cells was performed using a commercially available DNA Isolation kit (Invitrogen; Thermo Fisher Scientific, Inc.) according to the manufacturer's protocol. A mean total of $20 \mathrm{ng}$ of the DNA was isolated from each sample, and the purity of the isolates were assessed based on the OD260/280 spectrophotometric ratio (Implen NanoPhotometer; Implen $\mathrm{GmbH}$ ). Genotyping of the ACTN3 rs1815739 polymorphism was performed using reverse transcription-quantitative PCR on a QuantStudio 3 (Thermo Fisher Scientific, Inc.) using a TaqMan Genotyping assay according to the manufacturer's protocol (cat. no. 4362691; Thermo Fisher Scientific, Inc.). T (X allele) and $\mathrm{C}$ (R allele) alleles were determined using VIC and FAM primers, respectively (Fig. 1). The ACE InDel polymorphisms were genotyped using conventional PCR methodology as previously described (18). Amplification products were visualized under a UV light following electrophoresis on a $2 \%$ agarose gel stained with ethidium bromide. The 490 bp amplicons were considered the I allele, and the $190 \mathrm{bp}$ amplicon was considered the D allele (Fig. 2). The sequences of the primers used for genotyping are listed in Table I.
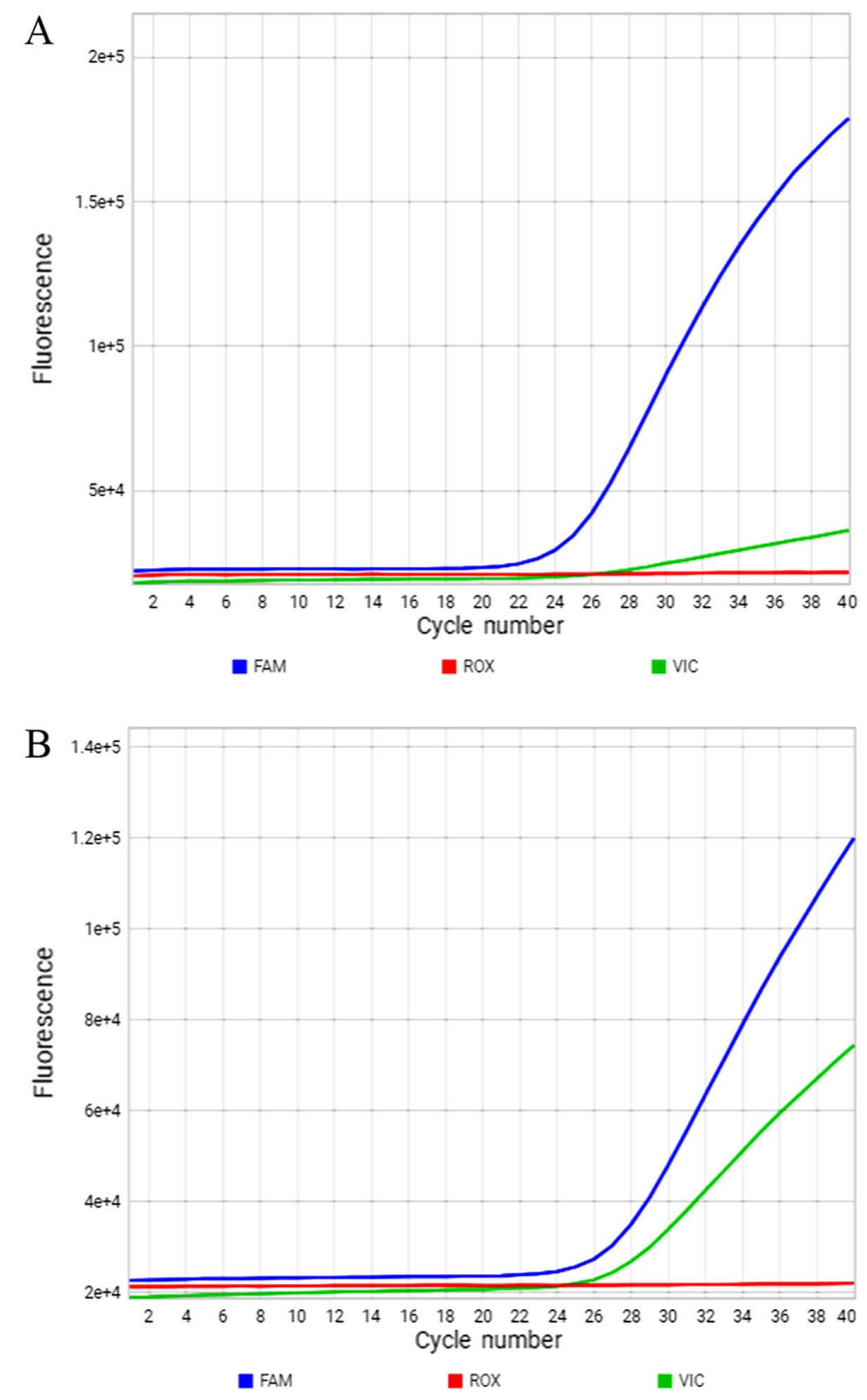

Figure 1. Quantitative PCR amplification of the RR (CC) genotype and RX (CT) genotype of ACTN3 rs1815739 polymorphism. FAM indicates the C allele (blue curve), whereas VIC (green curve) indicates the T allele). (A) The single blue curve indicates the homozygous genotype of RR (CC), whereas (B) the blue and green curves indicate the heterozygous genotype of RX (CT).

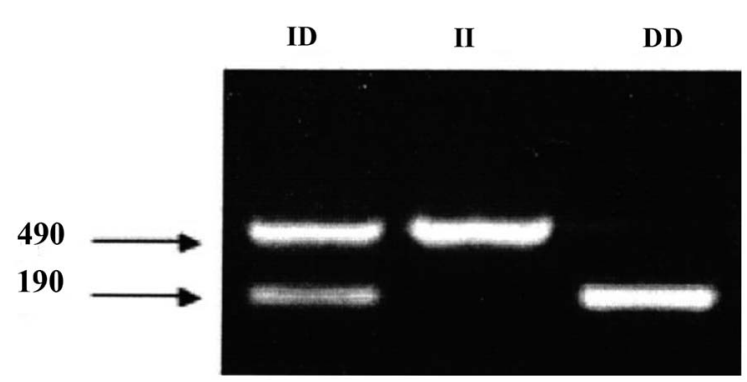

Figure 2. Representative image amplification products of the $A C E$ InDel polymorphisms run on an agarose gel. The band $490 \mathrm{bp}$ in length is the I allele, with a 287 bp insert. The 190 bp band is the D allele.

\section{Results}

The numbers and percentages of the $A C E$ InDel polymorphism in the examined bodybuilders were $2(18 \%), 8(73 \%)$ and $1(9 \%)$ for II, ID, and DD genotypes, respectively. For the $A C T N 3$ genotype, the respective numbers and frequencies 
Table I. Sequences of the primers used for genotyping ACTN3 rs1815739 and ACE InDel polymorphisms.

ACTN3 rs1815739 polymorphism

\section{$\mathrm{X}$ allele}

$\mathrm{R}$ allele

$A C E$ InDel polymorphism

Forward

Reverse
Sequence, 5'-3'

CAAGGCAACACTGCCCGAGGCTGACTGAGAGCGAGGTGCCATCATGGGCAT CAAGGCAACACTGCCCGAGGCTGACCGAGAGCGAGGTGCCATCATGGGCAT

ACTN3, $\alpha$-actinin-3; ACE, angiotensin converting enzyme.

Table II. Frequency of the $A C E$ and $A C T N 3$ genotypes and alleles.

\begin{tabular}{|c|c|c|c|c|c|}
\hline \multirow{2}{*}{$\begin{array}{l}\text { Polymorphism } \\
A C E \text { InDel }\end{array}$} & \multicolumn{3}{|c|}{ Genotype } & \multicolumn{2}{|c|}{ Allele } \\
\hline & DD & ID & II & $\mathrm{D}$ & I \\
\hline Number & 1 & 8 & 2 & 10 & 12 \\
\hline Percentage & 9.09 & 72.73 & 18.18 & 45.45 & 54.55 \\
\hline ACTN3 rs1815739 & $\mathrm{RR}$ & $\mathrm{RX}$ & XX & $\mathrm{R}$ & $\mathrm{X}$ \\
\hline Number & 5 & 6 & 0 & 16 & 6 \\
\hline Percentage & 45.45 & 54.55 & 0 & 72.73 & 27.27 \\
\hline
\end{tabular}

ACTN3, $\alpha$-actinin-3; ACE, angiotensin converting enzyme.

were $6(55 \%)$ and $5(45 \%)$ for the RX and RR genotypes. No $\mathrm{XX}$ genotypes were detected. The allelic count for the $A C E$ InDel polymorphisms were $12(55 \%)$ for I and $10(45 \%)$ for $\mathrm{D}$ allele; and $12(55 \%)$ for $\mathrm{R}$ and $10(45 \%)$ for the $\mathrm{X}$ allele for the ACTN3 rs1815739 polymorphism. Table II lists the genotype and allelic frequencies of the $A C E$ InDel and ACTN3 rs1815739 polymorphisms.

A total of five different genotype combinations were detected in the present study. None of the bodybuilders were $\mathrm{DD}+\mathrm{RR}$, three of the bodybuilders were ID + RR, five bodybuilders had ID + RX, one bodybuilder had II + RX and one bodybuilder had a II + RR genotype combination. Table III lists the genotype groups of the examined polymorphisms in the bodybuilders.

\section{Discussion}

Recent studies have shown that certain genes are effective in determining the performance of an athlete, both physiologically and psychologically $(5,8)$. To achieve the desired results, genetic models can be developed and used to find the optimal genetic endowment of athletes. The combinations of these genetic endowments may prove useful for sports scientists to set up personally modified training regimens. The present study examined the association between the ACE InDel and ACTN3 rs1815739 polymorphisms in 11 Turkish bodybuilders. The RX genotype for the ACTN3 genotype was higher
Table III. Genotype combination for the ACTN3 rs1815739 and $A C E$ InDel polymorphisms.

\begin{tabular}{llccc}
\hline \multirow{2}{*}{ Ace InDel } & & \multicolumn{3}{c}{ ACTN3 $\mathrm{rs1815739}$} \\
\cline { 4 - 5 } Polymorphism, n (\%) & & $\mathrm{RR}$ & $\mathrm{RX}$ & $\mathrm{XX}$ \\
\hline $\mathrm{DD}$ & $1(9.09)$ & - & - \\
$\mathrm{ID}$ & $3(27.27)$ & $5(45.46)$ & - \\
II & $1(9.09)$ & $1(9.09)$ & - \\
\hline
\end{tabular}

$A C T N 3, \alpha$-actinin-3; ACE, angiotensin converting enzyme.

compared with RR, and no XX genotypes were detected. The $\mathrm{R}$ allele, which is considered to be the wild-type allele, is associated with the rapid contraction of the sarcomeres, and thus considered superior (4).

In a study conducted on Russian football players; 240 football players were examined, and $46.25 \%$ had the RR genotype (19). Santiago et al (20) analysed 60 Brazilian football players and showed that $48.3 \%$ of the players in their cohort had the RR genotype. Roth et al (21) examined the frequency of the same polymorphism in both Black and White elite-level bodybuilders and compared them to the general population. They reported that the XX genotype was underrepresented in the bodybuilders. The results of the present study agree with these previous studies, showing that the incidence of the XX genotype in the bodybuilders was lower. Specifically, no volunteers harboured a XX genotype. Ulucan et al (15) reported the importance of an $\mathrm{R}$ allele in young Turkish sprinters in a study in which they compared trained and untrained young sprinters. Additionally, it has been reported that a higher percentage of the RR genotype and R allele was observed in 518 athletes in different disciplines (16). Dissimilar to these previous studies, the RX genotype percentage was higher in the present study, although the relatively smaller cohort size may account for the high percentage of the RX genotype. Regarding the ACTN3 rs1815739 polymorphism, no data regarding Turkish bodybuilders was found, thus the results could not be compared.

In the present study, $73 \%$ of the bodybuilders had the ID genotype, $18 \%$ had the II, and $9 \%$ had DD genotypes of $A C E$ InDel polymorphisms. The allelic count revealed an I allele in $55 \%$ of the bodybuilders. The ACE I allele is associated with low serum and tissue ACE enzyme activity, whereas the ACE II 
genotype is associated with endurance performance (22), consistent with the results of the present study. The prevalence of the D allele in athletes was more common in individuals who participated in sports requiring power and speed, such as sprinting (23). Suel et al (24) concluded that there was no significant difference between basketball players and volleyball players with regards to the $A C E$ InDel polymorphism, but reported that the ACE II genotype was associated with a larger $\mathrm{VO} 2_{\text {max }}$ compared with $A C E$ DD genotype individuals. However, the $A C E$ genotypes were not associated with any submaximal variables associated with physical fitness (25). Thus, further studies are required to clarify the influence of the $A C E$ polymorphism on the submaximal variables associated with aerobic fitness. Ulucan and Göle (26) analysed InDel polymorphisms in windsurfers and reported that the endurance related I allele was more prevalent in windsurfers.

Regarding the ACTN3 rs1815739 polymorphism, data on $A C E$ InDels in Turkish athletes was not found. Thus, the findings could not be compared with other Turkish based studies.

The cumulative effect of genotypes on human metabolism has always been of great relevance. To identify the optimal genotypes, several studies have examined potential candidate genes individually in different populations, and created a pool of genomic data. Genotype combinations are beneficial for defining a certain metabolic trait, or at least a part of a metabolic trait if they are part of a similar reaction (27). The present study may serve as an introductory study, upon which further studies can build, using larger cohorts and athletes with different specialities, to evaluate the effect of the combinations of these polymorphisms more accurately.

The small sample size is the primary limitation of the present study. In sports genetic studies, it is important to recruit a cohort with the same, or similar training regimens to minimise the influence of other factors, and increase confidence in the differences being caused by genetic determinants. Therefore, this type of studies does not commonly require sedentary groups. The bodybuilders in the present cohort had similar training programs, which is why they were recruited, but also underlies the reasoning behind the use of a smaller cohort. The second limitation of the present study was that data regarding baseline physical and physiological characteristics of the volunteers, such as muscle strength and mass, as well as the endurance capacities was not obtained for association analysis between the genotypes and these factors. Finally, there are no studies assessing Turkish bodybuilders, to the best of our knowledge, so the results cannot be compared, and how representative the results were could not be determined.

In conclusion, the present study is the first report examining the distribution of ACE InDel and ACTN3 rs1815739 polymorphisms in Turkish bodybuilders. The ACTN3 RX genotype and $\mathrm{R}$ allele and $A C E$ ID genotype and I allele were the most commonly observed polymorphisms in the present study. The high incidence of the I allele in the bodybuilders group coincided with previous sports genetics studies. These results suggest that the ACE InDel and ACTN3 rs1815739 polymorphism is an important determinant of a beneficial predisposition to certain sports or physical activities. Based on the results of the present study and our previous studies, it is hypothesized that bodybuilders are more likely to exhibit genotypes associated with endurance and power. These polymorphisms, which exist either alone, or in combination with the additional polymorphisms, should be considered when deciding on a genomic score profiles to improve an athletes chance of success in certain sports.

\section{Acknowledgements}

Not applicable.

\section{Funding}

No funding was received.

\section{Availability of data and materials}

The datasets used and/or analysed during the present study are available from the corresponding author on reasonable request.

\section{Authors' contributions}

TP and CSD obtained the genetic profiles of the volunteers. MD designed the study protocol. TA and KU designed the study and evaluated the results. KU wrote and revised the manuscript. All authors read and approved the final manuscript.

\section{Ethics approval and consent to participate}

The protocol used in the present study was approved by the Üsküdar University Ethics Committee and was performed in accordance with the principles of the Declaration of Helsinki II. All the volunteers were informed of the experimental procedure and any potential ethical implications, and all the participants provided written informed consent.

\section{Patient consent for publication}

Not applicable.

\section{Competing interests}

The authors declare that they have no competing interests.

\section{References}

1. Corak A, Kapıcı S, Sercan C, Akkoç O and Ulucan K: A pilot study for determination of anxiety related SLC6A4 promoter ' $S$ ' and ' $L$ ' alleles in healthy Turkish athletes. Cell Mol Biol (Noisy-le-grand) 63: 29-31, 2017.

2. Ulucan K, Kaman T, Kapıcı S, Sercan C and Konuk M: The determination of Alpha-Actinin-3 R577X polymorphisms distribution in Turkish national cyclists. Eurasian Research in Sport Science 2: 41-47, 2017.

3. Grover VK, Verma JP, Kumar A, Sharma N and Tiwari KP: A statistical model for ACTN3 genotype in elite power and speed athletes. J Stat Manag Sys 23: 239-248, 2020.

4. Ulucan K: Literature review of Turkish sportsmen in terms of ACTN3 R577X polymorphism. Clin Exp Health Sci 6: 44-47, 2016.

5. Eken BF, Akpınaroğlu C, Arslan KS, Sercan C and Ulucan K: Effects of genes to psychological factors in sports. J Neurobehav Sci 5: 56-61, 2018

6. Helms ER, Aragon AA and Fitschen PJ: Evidence-based recommendations for natural bodybuilding contest preparation: Nutrition and supplementation. J Int Soc Sports Nutr 11: 20, 2014. 
7. Verdijk LB, Jonkers RA, Gleeson BG, Beelen M, Meijer K, Savelberg HH, Wodzig WK, Dendale P and van Loon LJ: Protein supplementation before and after exercise does not further augment skeletal muscle hypertrophy after resistance training in elderly men. Am J Clin Nutr 89: 608-616, 2009.

8. Montgomery HE, Marshall R, Hemingway $\mathrm{H}$, Myerson S, Clarkson P, Dollery C, Hayward M, Holliman DE, Jubb M, World M, et al: Human gene for physical performance. Nature 393: 221-222, 1998

9. Rigat B, Hubert C, Alhenc-Gelas F, Cambien F, Corvol P and Soubrier F: An insertion/deletion polymorphism in the angiotensin I-converting enzyme gene accounting for half the variance of serum enzyme levels. J Clin Invest 86: 1343-1346, 1990.

10. Danser AH, Schalekamp MA, Bax WA, van den Brink AM, SaxenaPR, RieggerGA and Schunkert H: Angiotensin-converting enzyme in the human heart. Effect of the deletion/insertion polymorphism. Circulation 92: 1387-1388, 1995.

11. Eroğlu O, Zileli R, Nalbant MA and Ulucan K: Prevalence of alpha actinin-3 gene (ACTN3) R577X and angiotensin converting enzyme (ACE) insertion/deletion gene polymorphisms in national and amateur Turkish athletes. Cell Mol Biol (Noisy le Grand) 64: 24-28, 2018.

12. Puthucheary Z, Skipworth JR, Rawal J, Loosemore M, Van Someren K and Montgomery HE: Genetic influences in sport and physical performance. Sports Med 41: 845-859, 2011.

13. Zhang Q, Cao Y, Chen J, Shen J, Ke D, Wang X, Ji J, Xu Y, Zhang W, Shen Y, et al: ACTN3 is associated with children's physical fitness in Han Chinese. Mol Genet Genomics 294: 47-56, 2019.

14. Kikuchi N and Nakazato K: Effective utilization of genetic information for athletes and coaches: Focus on ACTN3 R577X polymorphism. J Exercise Nutrition Biochem 19: 157-164, 2015.

15. Ulucan K, Bayyurt GM, Konuk M and Güney AI: Effect of alpha-actinin-3 gene on Turkish trained and untrained middle school children's sprinting performance: A pilot study. Biol Rhy Res 45: 509-514, 2015.

16. Ulucan K, Göle S, Altindas N and Güney A: Preliminary findings of $\alpha$-actinin-3 gene distribution in elite Turkish wind surfers. Balkan J Med Genet 16: 69-72, 2013.

17. World Medical Association (WMA): WMA Declaration of Helsinki - ethical principles for medical research involving human subjects. https://www.wma.net/policies-post/wma-declaration-ofhelsinki-ethical-principles-for-medical-research-involving-humansubjects/. Accessed July 2018.
18. Guney AI, Ergec D, Kirac D, Ozturhan H, Caner M, Koc G, Kaspar K, Ulucan K and Agirbasli M: Effects of ACE polymorphisms and other risk factors on the severity of coronary artery disease. Genet Mol Res 12: 6895-6906, 2013.

19. Egorova ES, Borisova AV, Mustafina LJ, Arkhipova AA, Gabbasov RT, Druzhevskaya AM, Astratenkova IV and Ahmetov II: The polygenic profile of Russian football players. J Sports Sci 32: 1286-1293, 2014

20. Santiago C, González-Freire M, Serratosa L, Morate FJ, Meyer T, Gómez-Gallego F and Lucia A: ACTN3 genotype in professional soccer players. Br J Sports Med 42: 71-73, 2008.

21. Roth S, Walsh S, Liu D, Ferrucci JM and Hurley B: The ACTN3 $\mathrm{R} 577 \mathrm{X}$ nonsense allele is under-represented in elite-level strength athletes. Eur J Hum Genet 16: 391-394, 2008.

22. Guth LM and Roth SM: Genetic influence on athletic performance. Curr Opin Pediatr 25: 653-658, 2013.

23. Sercan C, Eken BF, Erel S, Ülgüt D, Kapıcı S and Ulucan K: The relationship of sports genetics and ACE gene. Inonu University, Journal of Physical Education and Sport Sciences 3: 26-34, 2016.

24. Süel E and Pehlivan A: Comparison of angiotensin converting enzyme (ACE) gene polymorphisms in elite basketball players and volleyball players. International Journal of Sport Exercise and Training Sciences 1: 40-50, 2015.

25. Orysiak J, Mazur-Różycka J, Busko K, Gajewski J, Szczepanska B and Malczewska-Lenczowska J: Individual and combined influence of ACE and ACTN3 genes on muscle phenotypes in polish athletes. J Strength Cond Res 32: 2776-2782, 2018.

26. Ulucan $\mathrm{K}$ and Göle S: ACE I/D polymorphism determination in Turkish elite windsurfers. Sport Sci 23: 79-84, 2014.

27. Ulucan K, Sercan, C and Biyikli T: Distribution of angiotensin-1 converting enzyme insertion/deletion and $\alpha$-actinin-3 codon 577 polymorphisms in Turkish male soccer players. Genet Epigenet 7: $1-4,2015$

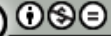

This work is licensed under a Creative Commons Attribution-NonCommercial-NoDerivatives 4.0 International (CC BY-NC-ND 4.0) License. 